\title{
TVR and vibration-induced timing of motor impulses in the human jaw elevator muscles ${ }^{1}$
}

\author{
K - E H A G B ARTH ${ }^{2}$, G. HELLSING, ANDL. LÖFSTEDT \\ From the Department of Clinical Neurophysiology, Academic Hospital, Uppsala, and \\ Department of Stomatognathic Physiology, Faculty of Odontology, Göteborg, Sweden
}

SYNOPSIS In order to investigate myotatic reflex involvement in jaw muscle control, an analysis was made of the motor responses induced by mechanical vibration $(120-160 \mathrm{~Hz})$ of the jaw elevator muscles in healthy subjects. As seen in torque measurements and mean-voltage electromyographic (EMG) recordings, the vibration caused involuntary reciprocal changes in jaw muscle tone, the contraction force increasing in jaw elevators and decreasing in antagonistic jaw opening muscles. This tonic vibration reflex (TVR) elicited from the jaw elevators exhibited many characteristics similar to those previously described for limb muscle tonic vibration reflexes: it varied in strength from one subject to the next independently of the briskness of the jaw elevator tendon jerks; it had a gradual onset with successive recruitment of jaw elevator motor units firing largely out of phase with one another and at rates much lower than the vibration frequency; it was susceptible to voluntary control-when allowed visual feed-back from the torque meter all subjects were able to suppress the TVR and keep mean contraction force constant. The results indicate that with respect to the tonic motor response to sustained inflow in the Ia afferent nerve fibres, the jaw elevators do not differ markedly from other skeletal muscles. Independently of whether a TVR was present or not, the vibration caused a timing of the motor unit discharges in the jaw elevators that could not be controlled voluntarily and that showed up in gross EMG recordings as a marked grouping of discharges synchronous with each wave of vibration. A similar but less distinct grouping of the gross EMG pattern was seen in limb muscles exposed to vibration, the dispersion increasing with the peripheral conduction distances of the reflex arcs. It is suggested that contrary to the TVR, which depends on the sustained mean level of the Ia afferent input, the timing phenomenon depends, like the tendon jerk, on the degree of synchrony in the afferent Ia volleys. Monosynaptic projections may well be involved in the dynamic timing of motor discharges during tonic firing, but this does not imply that the TVR or the tonic stretch reflex is dependent upon such projections.

The major jaw closing muscles in man (masseter, temporalis, medial pterygoid) are known to contain a large number of muscle spindles of similar shape to those found in limb muscles (Cooper, 1960), and in most subjects phasic stretch reflexes (tendon jerks) in

\footnotetext{
${ }^{1}$ The study was supported by the Swedish Medical Research Council. (Proj. no. B75-04X-2881-06A).

2 Address for reprint requests: K. E. Hagbarth, Department of Clinical Neurophysiology, Academic Hospital, Uppsala, Sweden.

(Accepted 10 February 1976.)
}

the jaw elevators are easily elicited. Animal cxperiments indicate that the jaw elevator muscle spindles have primary and secondary endings with receptive characteristics similar to those in limb muscles (Cody et al., 1972). Furthermore, increased spindle afferent firing has been seen during active jaw closure, suggesting that jaw elevator contractions are accompanied by a fusimotor activation of the spindle endings (Taylor and Davey, 1968; Matsunami and Kubota, 1972). Diverging opinions 
still exist, however, regarding the functional role of the phasic and tonic stretch reflex in the control of masticatory movements and jaw elevator muscle tone. According to Goodwin and Luschei (1974), mastication in the monkey is relatively undisturbed by lesions in the mesencephalic nucleus of the $\mathrm{V}$ nerve interrupting spindle afferent inflow from the jaw elevators. On the assumption that spindle inflow plays a similar role for jaw elevators as for other skeletal muscles, they conclude that the 'special theories implicating the muscle afferents as the major source of feed-back in the control of movement and posture have been overambitious'.

The muscle vibration technique provides another way of studying the physiological significance of the stretch reflexes in jaw movement control. Vibration of human limb muscles, known to be a potent stimulus for spindle receptors (Hagbarth, 1973; Burke et al., 1976) have been shown to induce rather potent motor and perceptual events. Apart from vibration-induced positional illusions (Goodwin et al., 1972; Eklund, 1972a) and dysequilibrium reactions resulting from leg muscle vibration during standing (Eklund, 1972b), the following vibration-induced motor effects have been described:

1. A tendency for the vibration waves to affect the timing of motor unit discharges during sustained contractions, so that the gross electromyographic pattern becomes synchronized to the vibration (Sommer, 1941; Hufschmidt, 1958; Homma et al., 1971; Hirayama et al., 1974).

2. A tonic reflex contraction tends to develop in the muscles exposed to the vibratory stimulus and at the same time reciprocal relaxation can be demonstrated in antagonistic muscles (tonic vibration reflex, TVR, for review see Hagbarth, 1973). There is evidence indicating that unlike $\mathrm{H}$ - and tendon jerk reflexes, the limb muscle TVR to a large extent depends on polysynaptic projections from the primary spindle endings (De Gail et al., 1966; Lance et al., 1966; Kanda, 1972).

Ito (1974) reported that TVR contractions similar to those previously studied in limb muscles can be elicited in the human masseter muscle. However, Godaux and Desmedt (1975a) analysing the EMG pattern of the TVR in the jaw elevators, described a vibration reflex with 'unexpected features': the motor unit potentials presented a close and highly consistent temporal relation to the vibration cycles, the small latency jitter being indicative of monosynaptic action (see also Desmedt and Godaux, 1975). For the TVR in limb muscles the latency jitter was found to be larger, exceeding the latency fluctuations of the tendon jerk reflex (Godaux et al., 1975). These findings were taken as evidence for genuine differences in TVR organization in jaw elevators and limb muscles.

The main aim of the present study was to gain further knowledge of the motor responses induced by jaw elevator vibration, and in particular to search for evidence that would elucidate whether the phasic and tonic stretch reflexes play a different functional role for the jaw elevators than they do for other skeletal muscles.

\section{METHODS}

The experiments were performed on three femal and four male adult subjects, all of them healthy with well-preserved dentition and no sign of mandibular dysfunction.

The subject was seated in a comfortable chair with the skull in a fixed position. EMG activity was recorded bilaterally from the jaw elevators (masseter and/or temporalis) and from the jaw opening suprahyoid muscles. Jaw muscle torque was recorded isometrically: jaw elevation with a strain gauge built into a rigid, $10 \mathrm{~mm}$ thick mouth piece placed between the front teeth, jaw opening with another strain gauge transducer positioned under the chin while the skull was fixed.

EMG was recorded either with a pair of $9 \mathrm{~mm}$ silver disc electrodes placed $2 \mathrm{~cm}$ apart, or with coaxial needle electrodes. The signals were amplified by Tektronix 122 preamplifiers and displayed on a Mingograph 800 or on a Tektronix 549 oscilloscope. An R-C 'integrating' network (time constant $0.1 \mathrm{~s}$ ) was used to produce a mean voltage display of the EMG activity. The force signals were amplified and displayed together with the electromyograms.

The vibrator used was an electric motor with an eccentric load. It was manually applied and had a contact area of about $2 \mathrm{~cm}^{2}$. Different sites of 
application were tried but the standard place of application was over one of the masseter muscles about $3 \mathrm{~cm}$ below the zygomatic bone. By changing the eccentric load the vibration amplitude could be varied from 1.5 to $0.2 \mathrm{~mm}$, and, for reasons to be described below, the latter amplitude was chosen as standard. The vibration frequency could be altered by changing the speed of the motor, the standard being $160 \mathrm{~Hz}$. The mean vibrator pressure upon the tissues, measured with a strain gauge attached to the vibrator was normally kept at 15 Newton (N). When studying the timing of motor discharges in relation to the vibration wave, the beam of the oscilloscope was triggered by the output of an Endevco 2222A accelerometer attached to the vibrator.

All subjects received clear instructions of how to behave during the vibration tests. In the standard 'constant effort' tests the subject was instructed to maintain a moderate steady voluntary effort in pressing the jaw up or down-that is, he was not allowed to compensate for those vibration-induced changes in force that he might perceive. In those tests in which voluntary control of the TVR was studied, the subject was instructed to compensate for the developing TVR, so as to keep the biting or jaw opening force constant. The latter 'constant force' tests were done with or without visual feed-back, achieved by letting the subject watch the strain gauge meter.

\section{RESULTS}

EFFECTS ON BITING AND JAW-OPENING FORCE In all 'constant effort' bite tests vibration (160 $\mathrm{Hz}$ ) of the jaw elevators caused a slowly rising increase in biting force. All subjects perceived this force change, some of them even described it as an uncomfortable cramp-like feeling in the jaw elevators. The strength of the motor response increased with increasing vibration amplitude and so did the cramp-like sensations, especially when the vibratory stimulus lasted for more than $30 \mathrm{~s}$. A vibration amplitude of $0.2 \mathrm{~mm}$ usually did not cause any discomfort, and therefore this relatively small vibration amplitude was chosen as standard.

A vibration-induced jaw clenching response could be elicited from various regions of the lower jaw (front of chin, lateral aspects of corpus and ramus of the mandible and mandibular front teeth). In all subjects, however, the strongest motor responses occurred when vibration was applied over one of the jaw elevator muscles: masseter or temporalis. Vibration over the temporalis muscle often caused an unpleasant feeling of dizziness, and therefore the site of application chosen as standard was over one of the masseter muscles.

When recorded under standardized conditions the strength and time course of the vibration-induced jaw clenching varied greatly from one subject to the next, whereas the intraindividual variations between succeeding tests were relatively minor. No correlation was observed between the strength of the tonic jaw clenching response and the briskness of the jaw elevator tendon jerks. Figure 1A shows that the mean biting force rose during vibration to more than twice the control value, which was about $15 \mathrm{~N}$ (less than $1 / 10$ of maximal biting force). After the start of vibration the force rose slowly until a plateau level was reached after 10-30 $\mathrm{s}$. When vibration lasted for more than one minute the plateau level remained relatively constant in some subjects whereas in others a slow decline was seen. On cessation of vibration it often took a number of seconds before the biting force returned to the original control value.

In 'constant effort' jaw-opening tests vibration of the jaw elevator caused a reduction of jaw opening force. Figure 1D shows that the mean opening force fell during vibration to about one-fifth of the control value, the optimal effect also in this case being reached after 10-30 s.

EFFECTS OF MASSETER VIBRATION AS SEEN IN MEAN-VOLTAGE EMG RECORDINGS During 'constant effort' biting a weak sustained EMG activity was present in both masseter muscles and sometimes also in the temporalis muscles, whereas the jaw opening muscles were silent. The increase in biting force caused by unilateral masseter vibration was accompanied by increased EMG activity both in ipsi- and contralateral jaw elevators, the jaw opening muscles remaining silent (Figs 2 and 3). In all subjects the mean EMG voltage rose to higher levels in the muscle underlying the vibrator than in the contralateral masseter muscle (Fig. 

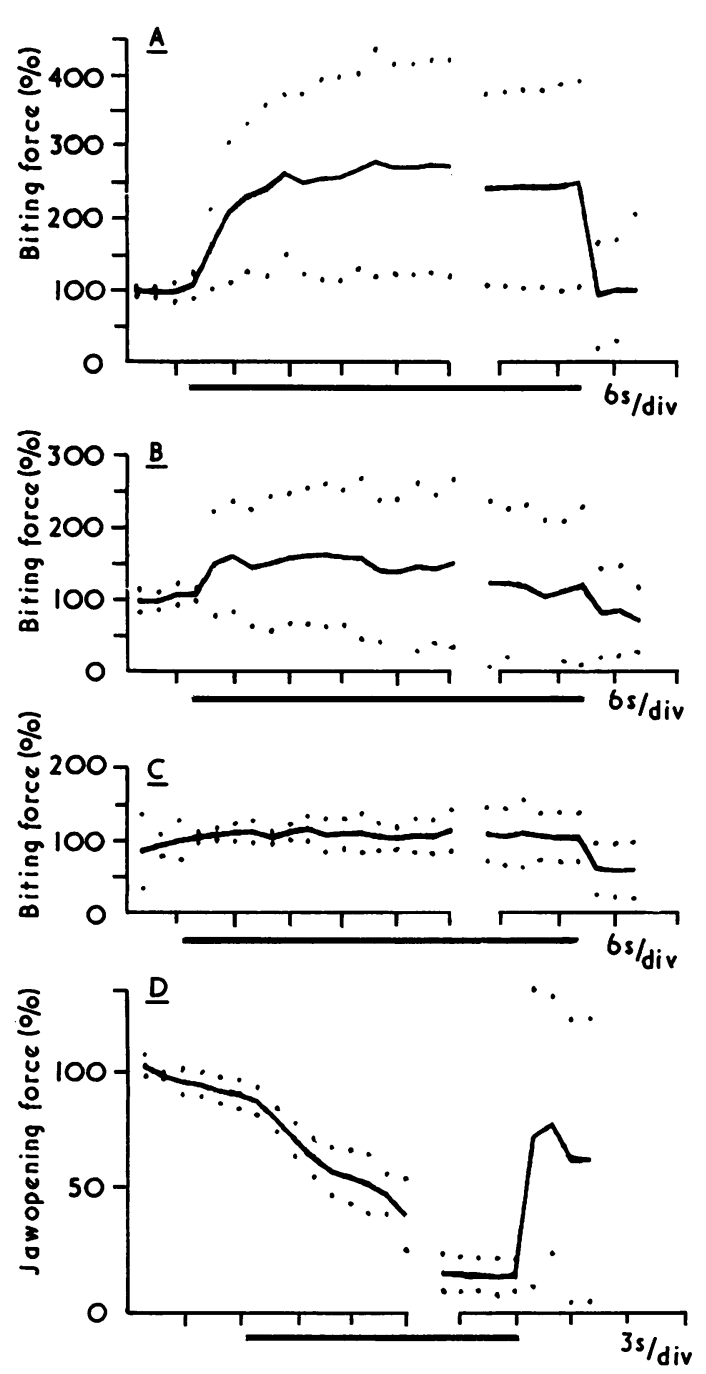

FIG. 1 Changes in biting and jaw opening force induced by vibration $(160 \mathrm{~Hz}, 0.2 \mathrm{~mm})$ on masseter muscle. $A$. 'Constant effort' bite tests. $B$. 'Constant force' bite tests without visual feedback from force meter. C. 'Constant force' bite tests with visual feed-back from force meter. $D$. 'Constant effort' jaw opening tests. Responses of seven subjects averaged in $A, B$ and $C$, responses of four subjects averaged in $D$ (mean $\pm 1 S D)$. Vibration indicated by bar below diagrams. $80 \mathrm{~s}$ omitted where traces are interrupted.

$3 \mathrm{~A}$ ), and also in the temporalis muscles the ipsilateral response was stronger than the contralateral one (Fig. 3B). The gradual onset of the motor response and its slow decline at the end of vibration was as well seen in the meanvoltage EMG as in the force traces (Fig. 2).

During 'constant effort' jaw opening a sustained EMG activity was present in the jaw opening muscles, whereas the jaw elevators were silent. The decrease in jaw opening force during unilateral masseter vibration was accompanied by a progressive decrease of the jaw opening EMG activity (Fig. 3C). In three of the four subjects exposed to this test no EMG activity appeared in the jaw elevators; in the fourth subject there was a weak masseter contraction accompanying the inhibition of the jaw openers.

VOLUNTARY CONTROL OF VIBRATION-INDUCED JAW CLENCHING The tonic motor responses described were not 'compulsory' but were susceptible to voluntary control. Thus, when given visual feedback from the force meter and instructed to counteract the motor effects of vibration, all subjects were able to maintain a rather constant level of EMG activity and force during the vibration tests. Figure $1 \mathrm{C}$ shows in mean values the extent to which the seven subjects, with the help of visual feedback, succeeded in maintaining constant bite force during vibration of the masseter muscle. They all succeeded quite well, and they reported that in order to keep pressure constant they had to make efforts as if to open the mouth. However, no EMG activity appeared in the jaw opening muscles. One subject reported a strong illusion of a slow jaw opening movement occurring during the test.

Figure 1B illustrates the subjects' ability to compensate for the vibration-induced force changes without the help of visual feed-back. The mean values give the impression of reasonable compensation (cf. Fig. 1A), but this results from the fact that under- and overcompensation occurred to an approximately equal extent. All subjects reported that in these tests they felt insecure about the amount of pressure exerted.

MOTOR UNIT RECRUITMENT DURING VIBRATION In the test illustrated in Fig. 4 the subject was instructed to relax completely in all jaw muscles and to remain passive while vibration 

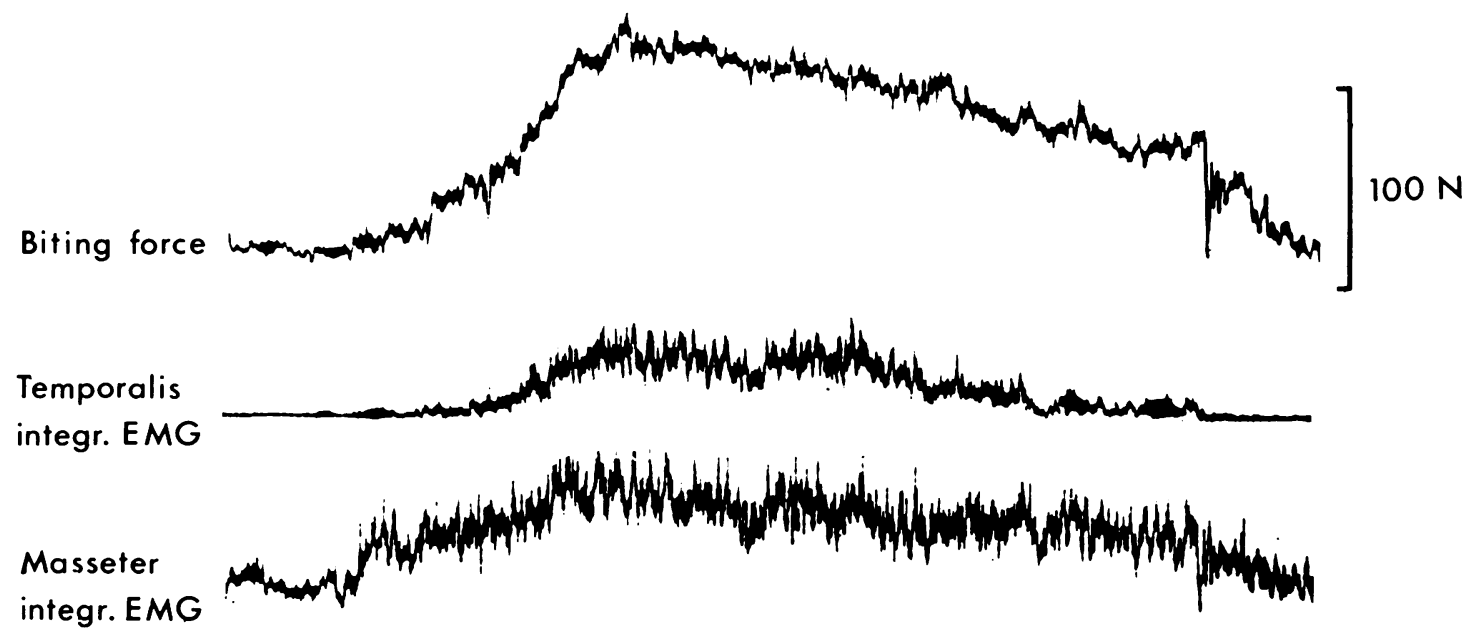

Suprahyoid integr. EMG

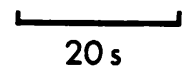

FIG. 2 Tonic jaw clenching response induced by vibration on left masseter muscle. 'Constant effort' test. Simultaneous recording of biting force (initially $15 \mathrm{~N}$ ) and mean voltage EMG from contralateral jaw elevators and jaw openers. Vibration $(160 \mathrm{~Hz}, 0.2 \mathrm{~mm})$ indicated by bar.

$(130 \mathrm{~Hz})$ was applied on the lateral aspect of the ramus of the mandible. After vibration for $4 \mathrm{~s}$ motor unit firing started in the masseter muscle initiating jaw closure. Gradual recruitment of motor units was seen, the individual units firing at rates of $15-20 \mathrm{~Hz}$, largely out of phase with each other. Similar recruitment patterns and firing rates were seen when, in the absence of vibration, the subject was instructed to initiate a slow voluntary jaw closure.

TIMING OF MOTOR DISCHARGES DURING VIBRATION.

Displays like that of Fig. 4 do not reveal that all motor unit discharges occur during a certain phase of the vibration wave (Godaux and Desmedt, 1975a; Desmedt and Godaux, 1975). This timing phenomenon was clearly seen when the EMG recordings were displayed on fast oscilloscope sweeps, triggered by the vibration wave, as in Figs 5A and 6A. However, it was not only the motor units recruited by vibration that fired during a certain phase of the vibration wave: discharges of voluntarily driven motor units in the masseter muscle also became phase-locked to the mechanical oscillations as soon as the vibrator was applied, and this phase locking remained throughout vibration irrespective of voluntary- or vibration-induced changes in contraction strength (Fig. 5B). Thus, contrary to the vibration-induced tonic contractions, the timing phenomenon was not susceptible to voluntary control.

For comparison, the vibration-induced timing of motor discharges was also studied in limb muscles with longer proprioceptive reflex arcs than the jaw elevators. Figure 6B and $C$ 


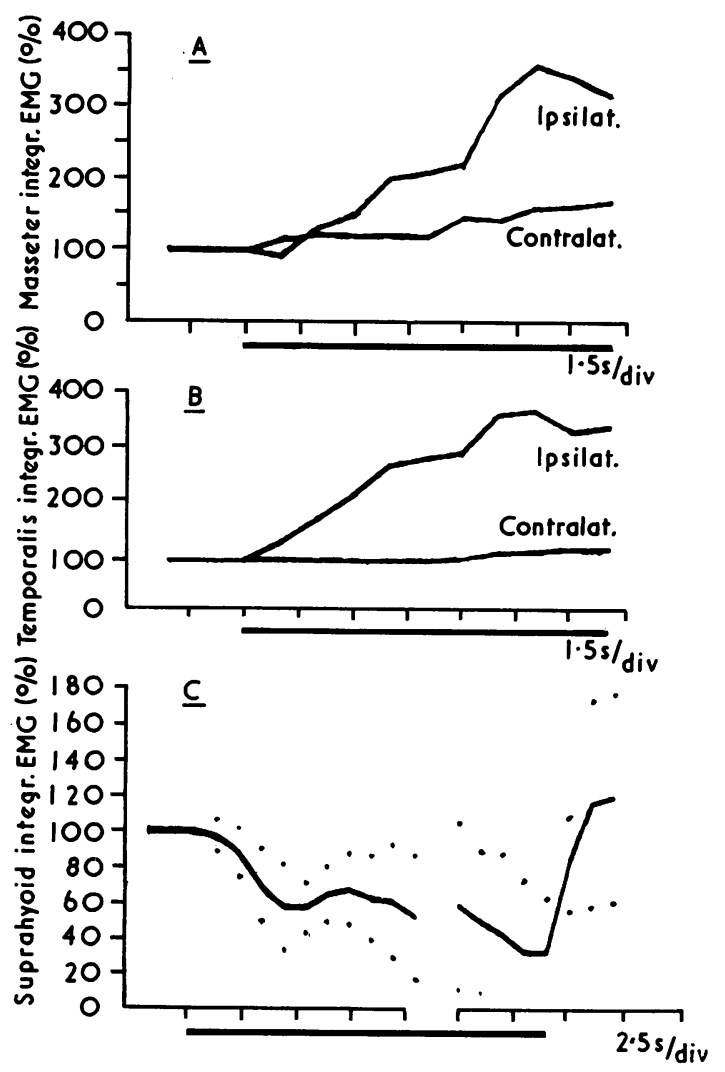

FIG. 3 Changes in jaw muscle EMG activity (mean voltage) induced by vibration $(160 \mathrm{~Hz}$, $0.2 \mathrm{~mm}$ ) on left masseter muscle. A. Recordings from ipsi- and contralateral masseter muscle during 'constant effort' biting. B. Recordings from ipsi- and contralateral temporalis muscle during 'constant effort' biting. C. Recordings from ipsilateral jaw opening muscles during 'constant effort' jaw opening. $30 \mathrm{~s}$ omitted where trace is interrupted. Responses of seven subjects averaged in $A$ and $B$, responses of four subjects averaged in $C$.
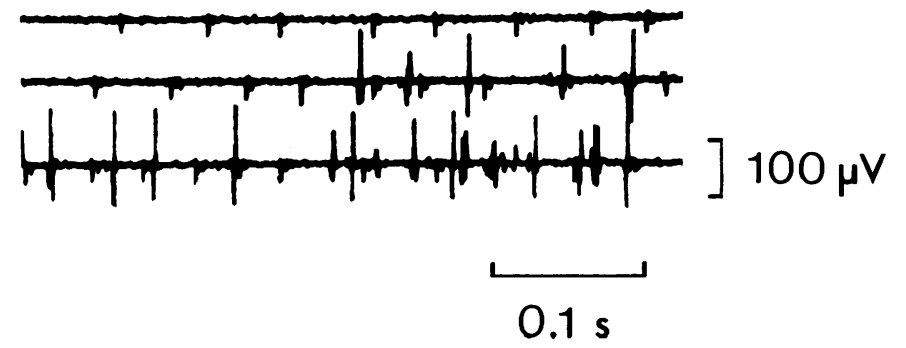

show how vibration of the patellar tendon affects the timing of motor discharges in the quadriceps muscle, and how vibration of the Achilles tendon affects the timing of triceps surae EMG potentials. The results indicate that the synchronizing effect of muscle vibration decreases with increasing conduction distances in the afferent and motor links of the proprioceptive reflex arcs. It should be stressed that the type of recording used illustrates the summed EMG response of a number of motor units. No comment can be made on the behaviour of single motor units, but these are the subject of study in a separate paper (Burke and Schiller, 1976).

\section{DISCUSSION}

SIMILARITIES BETWEEN TVR OF LIMB AND JAW ELEVATOR MUSCLES The changes in jaw muscle tone induced by vibration of the jaw elevators have many characteristics in common with the tonic vibration reflexes (TVR), previously described for human limb muscles (De Gail et al., 1966; Eklund and Hagbarth, 1966; Hagbarth and Eklund, 1966; Marsden et al., 1969). The slow onset both of the autogenetic excitatory and the reciprocal inhibitory effects have previously been described as typical for limb muscle tonic vibration reflexes in healthy subjects, and the same holds true for the subjects' ability to control the reflexes voluntarily. For similar reasons, as previously stated in the case of the limb muscle TVR (Hagbarth and Eklund, 1966), the primary endings of the jaw elevator muscle spindles are likely to be the receptors responsible for the vibration-induced reflex changes in jaw muscle tone. These are the only receptors

FIG. 4 Recruitment of motor units in right masseter muscle during tonic jaw clenching response elicited by vibration $(130 \mathrm{~Hz}, 1.2 \mathrm{~mm})$ on lateral aspect of jaw. Jaw elevators initially relaxed. Continuous recording shown in three successive sweeps, vibration starting $4 \mathrm{~s}$ before appearance of first $E M G$ potential in upper trace. 


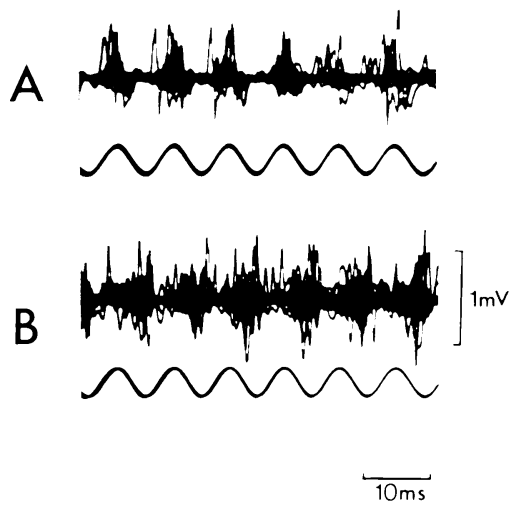

III. 5 The synchronizing effect of vibration on masseter EMG activity. Recordings from right masseter muscle during vibration $(120 \mathrm{~Hz}, 1.2 \mathrm{~mm})$ on lateral aspect of jaw. A. Motor units recruited by vibratory stimulus, firing in phase with vibration wave. Subject initially relaxed as in Fig. 4. B. Motor units activated voluntarily firing in phase with vibration wave. Subject maintaining 'constant force'. Superpositions of eight to 10 sweeps, triggered by vibration wave (lower traces).

known to fulfil the two criteria of being highly sensitive to vibration (Granit and Henatsch, 1956; Brown et al., 1967; Burke et al., 1976) and of evoking the reflex pattern of autogenetic excitation and reciprocal inhibition - that is, the classical pattern of the stretch reflex. It may be objected that the jaw elevator TVR contraction is not restricted to the muscle vibrated but also involves neighbouring and contralateral jaw elevators. This, however, can easily be explained in terms of mechanical spread of the vibratory stimulus along the mandibular bone, a fact supported by the findings that the ipsilateral contractions were always stronger than the contralateral ones. The reciprocal inhibitory effect upon jaw opening muscles, demonstrated in the present study, seems to contradict observations in the cat that Ia afferent volleys from the masseter muscle have no inhibitory effect upon antagonistic motoneurones (Kidokoro et al., 1968). However, as will be further discussed below, a clear distinction should be drawn between the tonic motor effects induced by sustained activity in Ia afferent fibres and the

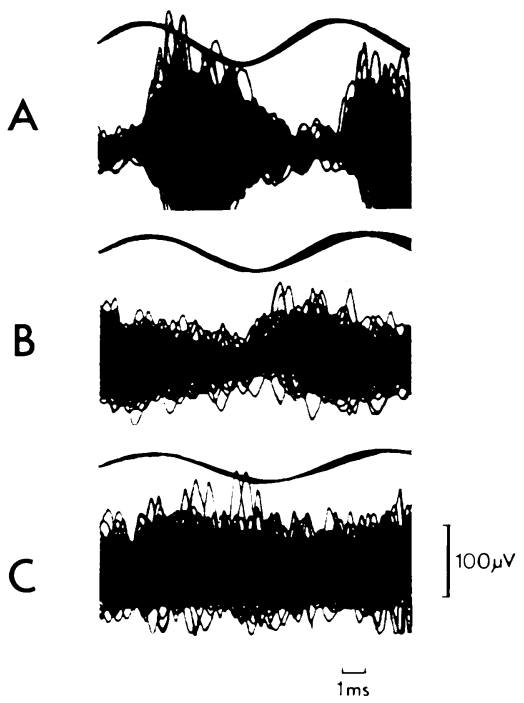

FI(i. 6 The synchronizing effect of vibration on EMG activity in jaw elevator as compared with limb muscles. Superpositions of 15 sweeps, triggered by vibration wave. Accelerometer signal in upper traces. A. Vibration-induced EMG in masseter muscle, during vibration $(125 \mathrm{~Hz}, 1.2 \mathrm{~mm})$ on lateral aspect of jaw (cf. Fig. 5A). B. Vibration-induced EMG in quadriceps muscle when patellar tendon is vibrated $(120 \mathrm{~Hz}, 1.2 \mathrm{~mm}) . \mathrm{C}$. Vibration-induced EMG from soleus muscle when Achilles tendon is vibrated $(115 \mathrm{~Hz}, 1.2 \mathrm{~mm})$.

dynamic reflex effects of synchronized volleys in the same afferent fibres. A lack of short latency reciprocal inhibitory responses to synchronized Ia volleys does not exclude long latency inhibitory effects from sustained inflow in the Ia afferent fibres.

VIBRATION-INDUCED TIMING OF MOTOR IMPULSES IN JAW AS COMPARED WITH LIMB MUSCLES The 'unexpected features' of the jaw elevator TVR described by Godaux and Desmedt (1975a) do not concern the tonic but the dynamic synchronizing effects of the vibratory stimulus. The present study confirms that in the human jaw elevators the synchronizing effect of vibration is potent enough to make the gross EMG pattern take the form of well defined bursts separated by intervals of silence. This high 
degree of synchrony even at high vibration frequencies is similar to that seen in cat limb muscles (Homma et al., 1972; Matthews, 1975). The present study also confirms previous observations that vibration-induced timing of motor impulses occurs in human limb muscles (Sommer, 1941; Hufschmidt, 1958; Homma et al., 1971; Hirayama et al., 1974), but here the synchrony was found to be less pronouncedthat is, in the gross EMG recordings motor impulses were dispersed in the intervals between successive bursts. This agrees with the larger latency jitter found by Godaux et al., (1975) for the motor unit discharges in the limb muscle TVR. A common denominator for the human jaw and cat limb muscles is the shortness of the reflex arcs, and this may be the main reason why the vibration rhythm is so distinctly reflected in the gross EMG pattern of these muscles during sustained contractions. The shorter the peripheral conduction distance, the less the Ia impulse volleys will be dispersed in the presynaptic terminals and the more effective will their trigger function be. Also, in gross EMG recordings there will be a dispersion of the motor impulse volleys, increasing with the motor conduction distance.

CENTRAL PATHWAYS RESPONSIBLE FOR TVR AND FOR VIBRATION-INDUCED TIMING PHENOMENON Intracellular recordings in the cat (Westbury, 1972; Homma and Kanda, 1973) indicate that the repetitive grouped discharges in Ia afferent fibres from a vibrated muscle are monosynaptically transmitted to homonymous alpha motoneurones causing repetitive excitatory postsynaptic potentials (EPSPs) with frequencies closely corresponding to that of vibration (tested range up to $300 \mathrm{~Hz}$ ). When motoneurone firing occurs the precise timing of individual motor discharges is critically dependent upon the monosynaptically transmitted EPSP 'ripple'. It is still uncertain, however, to what extent temporal summation of monosynaptic EPSPs are responsible for the gradual increase in depolarizing pressure that enhances the total output of the motoneurone pool-that is, that brings about the TVR contraction (Homma and Kanda, 1973; Matthews, 1975). According to Homma and Kanda (1973) the monosynaptic EPSP 'ripple' is often riding on top of a slowly rising depolarization which they attribute to Ia inflow mediated through polysynaptic pathways, and which they regard as the main generator of excitation. There is also evidence indicating that, whereas the strength of the TVR contraction increases with the mean level of the vibration-induced Ia input, it is not critically dependent on how the pulsatile Ia volleys are spaced in time (Matthews, 1975). One of the interpretations offered by Matthews to account for this 'smoothing' phenomenon is that the TVR is mediated to a large extent by polysynaptic pathways. This agrees with earlier studies in the cat indicating that polysynaptic pathways play a major role in the generation of the classical tonic stretch reflex (Granit et al., 1957).

There are several reasons for assuming that the tonic vibration reflex, as it appears both in human jaw and limb muscles, is largely mediated by polysynaptic pathways. Its slow onset and decline, the relative ease with which it can be controlled voluntarily, and its susceptibility to anaesthetic drugs are features indicative of progressive recruitment of polysynaptic paths (De Gail et al., 1966; Lance et al., 1966; Kanda, 1972). If temporal summation of monosynaptic EPSPs were of importance in generating the TVR one would expect that for any particular muscle in a given subject there would be some correlation between the strength of the TVR and the briskness of the monosynaptic tendon jerks. Both in jaw and limb muscles there is a striking lack of such correlation ( $c f$. Eklund and Hagbarth, 1966). According to Godaux and Desmedt (1975b), tendon jerk and H-reflex tests during ongoing vibration give diverging results in the masseter as compared with the soleus muscle: the phasic test reflexes being suppressed in the calf muscle, enhanced in the jaw elevator. They interpret their findings in terms of presynaptic inhibitory processes during vibration acting more strongly on limb than on masseter monosynaptic circuits. If this is the case, it may help to explain why masseter motor unit discharges have such a close temporal relationship to the vibration waves, but it provides no evidence for monosynaptic mechanisms playing a role 
in the build-up and maintenance of the jaw elevator TVR.

With the vibration technique commonly used in man, impulse volleys synchronized to the vibration wave are induced not only in the Ia afferent fibres but also in other types of mechanoreceptive fibres, including those with autogenetic inhibitory effects (Burke et al., 1976). If each beat of the vibrator induces a monosynaptic EPSP followed by an oligosynaptic IPSP a large membrane 'ripple' will result, which, even though it does not raise the mean depolarizing pressure, effectively locks the discharge of firing neurones to a certain phase of the vibration wave.

Recent findings in man support the notion that the central pathways responsible for the TVR are not identical with those responsible for the vibration-induced timing of motor impulses. Burke and Schiller (1976) observed that contrary to calf muscle vibration, low voltage (sub $\mathbf{M}$ wave) tetanic stimulation of the human tibial nerve at frequencies above $30 \mathrm{~Hz}$ gives no synchronization of motor impulses in the calf muscles. Still, the electrical stimulation induces a tonic reflex contraction in the triceps surae muscles, analogous to a TVR. Furthermore, an example of a vibration-induced tonic contraction without concomitant signs of mono- or oligosynaptic motor synchronization has been demonstrated by Hellsing (1976). He found that vibration applied on the jaw openers evokes a contraction in these muscles accompanied by reciprocal inhibition of the jaw elevators. Contrary to the jaw elevator TVR, however, this tonic jaw opening reflex is characterized by a lack of motor synchronization.

MYOTATIC REFLEX INVOLVEMENT IN JAW MUSCLE CONTROL The present results should not be regarded as contradictory to the findings of Goodwin and Luschei (1974) that the spindle afferent projections from the jaw elevators can be interrupted without causing major disturbances in jaw muscle tone. However, it does not seem presumptious to propose that, in a similar way as monosynaptic projections from jaw elevator spindle primaries normally assist in fast load compensating functions, the polysynaptic tonic stretch reflex assists in the maintenance of jaw elevator muscle tone. This does not imply that the reflex projections from the spindles are the sole or even the 'major source of feed-back' in the control of mastication. After elimination of the jaw elevator spindle feed-back other control systems, such as those involving joint afferent nerve fibres (Larsson and Thilander, 1964), periodontal receptors (Sessle and Schmitt, 1972), and skin receptors (Bratzlavsky, 1972; Yu et al., 1973; Godaux and Desmedt, 1975c) may efficiently compensate for the loss of the myotatic components.

\section{REFERENCES}

Bratzlavsky, M. (1972). Pauses in activity of human jaw closing muscle. Experimental Neurology, 36, $160-165$.

Brown, M. C., Engberg, I., and Matthews, P. B. C. (1967). The relative sensitivity to vibration of muscle receptors of the cat. Journal of Physiology, 192, 773-800.

Burke, D., Hagbarth, K-E. Löfstedt, L., and Wallin, G. (1976). The response of human muscle spindle endings to vibration of noncontracting muscles. Journal of Physiology. In press.

Burke, D., and Schiller, H. M. (1976). Discharge pattern of single motor units in the tonic vibration reflex of human triceps surae. Journal of Neurology, Neurosurgery, and Psychiatry, 39, 729-741.

Cody, F. W. J., Lee, R. W. H., and Taylor, A. (1972). A functional analysis of the components of the mesencephalic nucleus of the fifth nerve in the cat. Journal of Physiology, 226, 249-261.

Cooper, S. (1960). Muscle spindles and other muscle receptors. In The Structure and Function of Muscle, vol. 1, pp. 381-420. Edited by G. H. Bourne. Academic Press: New York.

De Gail, P., Lance, J. W., and Neilson, P. D. (1966). Differential effects on tonic and phasic reflex mechanisms produced by vibration in man. Journal of Neurology, Neurosurgery, and Psychiatry, 29, $1-11$.

Desmedt, J. E., and Godaux, E. (1975). Vibrationinduced discharge patterns of single motor units in the masseter muscle in man. Journal of Physiology, 253, 429-442.

Eklund, G. (1972a). Position sense and state of contraction. Journal of Neurology, Neurosurgery, and Psychiatry, 35, 606-611.

Eklund, G. (1972b). General features of vibrationinduced effects on balance. Upsala Journal of Medical Sciences, 77, 112-124. 
Eklund, G., and Hagbarth, K-E. (1966). Normal variability of tonic vibration reflexes in man. Experimental Neurology, 16, 80-92.

Godaux, E., and Desmedt, J. E. (1975a). Evidence for a monosynaptic mechanism in the tonic vibration reflex of the human masseter muscle. Journal of Neurology, Neurosurgery, and Psychiatry, 38, 161-168.

Godaux, E., and Desmedt, J. E. (1975b). Human masseter muscle: $\mathrm{H}$ - and tendon reflexes. Archives of Neurology (Chic.), 32, 229-234.

Godaux, E., and Desmedt, J. E. (1975c). Exteroceptive suppression and motor control of the masseter and temporal muscles in normal man. Brain Research, $85,447-458$.

Godaux, E., Desmedt, J. E., and Demaret, P. (1975). Vibration of human limb muscles: the alleged phase-locking of motor unit spikes. Brain Research, 100, 175-177.

Goodwin, G. M., and Luschei, E. S. (1974). Effects of destroying spindle afferents from jaw muscles on mastication in monkeys. Journal of Neurophysiology, 37, 967-981.

Goodwin, G. M., McCloskey, D. I., and Matthews, P. B. C. (1972). The contribution of muscle afferents to kinesthesia shown by vibration induced illusions of movement and by the effects of paralysing joint afferents. Brain, 95, 705-748.

Granit, R., and Henatsch, H. D. (1956). Gamma control of dynamic properties of muscle spindles. Journal of Neurophysiology, 19, 356-366.

Granit, R., Phillips, C. G., Skoglund, S., and Steg, G. (1957). Differentiation of tonic from phasic alpha ventral horn cells by stretch, pinna and crossed extensor reflexes. Journal of Neurophysiology, 20, 470-481.

Hagbarth, K-E. (1973). The effect of muscle vibration in normal man and in patients with motor disorders. In New Developments in Electromyography and Clinical Neurophysiology, vol. 3, pp. 428-443. Edited by J. E. Desmedt. S. Karger: Basel.

Hagbarth, K-E., and Eklund, G. (1966). Motor effects of vibratory muscle stimuli in man. In Proceedings of the First Nobel Symposium: Muscular Afferents and Motor Control, pp. 177-186. Edited by R. Granit. Almqvist and Wiksell: Stockholm.

Hellsing, G. (1976). A tonic vibration reflex evoked in the digastric muscle in man. Archives of Oral Biology. In press.

Hirayama, K., Homma, S., Mizote, M., Nakajima, Y., and Watanabe, S. (1974). Separation of the contributions of voluntary and vibratory activation of motor units in man by cross-correlograms. Japanese Journal of Physiology, 24, 293-304.

Homma, S., Kanda, K., and Watanabe, S. (1971). Tonic vibration reflex in human and monkey subjects. Japanese Journal of Physiology, 21, 419-430.
Homma, S., Kanda, K., and Watanabe, S. (1972). Preferred spike intervals in the vibration reflex. Japanese Journal of Physiology, 22, 421-432.

Homma, S., and Kanda, K. (1973). Impulse decoding process in stretch reflex. In Motor Control, pp. 4564. Edited by A. A. Gydikov, N. T. Tankov, and D. S. Kosarov. Plenum Press: New York.

Hufschmidt, H. J. (1958). Wird durch Muskelvibration eine Eigenreflexreihe erzeugt? Pflügers Archiv fürdie Gesamte Physiologie, 267, 508-516.

Ito, F. (1974). Tonic vibration reflex. Bulletin of the Tokyo Medical Dental University, 21, suppl, 37-40.

Kanda, K. (1972). Contribution of polysynaptic pathways to the vibration reflex. Japanese Journal of Physiology, 22, 367-377.

Kidokoro, Y., Kubota, K., Shuto, S., and Sumino, R. (1968). Reflex organization of cat masticatory muscle. Journal of Neurophysiology, 31, 695-708.

Lance, J. W., De Gail, P., and Neilson, P. D. (1966). Tonic and phasic spinal cord mechanisms in man. Journal of Neurology, Neurosurgery, and Psychiatry, 29, 535-544.

Larsson, L-E., and Thilander, B. (1964). Mandibular positioning. The effect of pressure on the joint capsule. Acta Neurologica Scandinavica, 40, 131-143.

Marsden, C. D., Meadows, J. C., and Hodgson, H. J. F. (1969). Observations on the reflex response to muscle vibration in man and its voluntary control. Brain, 92, 829-846.

Matsunami, K., and Kubota, K. (1972). Muscle afferents of trigeminal mesencephalic tract nucleus and mastication in chronic monkeys. Japanese Journal? of Physiology, 22, 545-555.

Matthews, P. B. C. (1975). The relative unimportance of the temporal pattern of the primary afferent input in determining the mean level of motor firing in the tonic vibration reflex. Journal of Physiology, 251, 333-361.

Sessle, B. J., and Schmitt, Adrianne (1972). Effects of controlled tooth stimulation on jaw muscle activity in man. Archives of Oral Biology, 17, 1597-1607.

Sommer, J. (1941). Synchronisierung motorischer Impulse und ihre Bedeutung für die Neurophysiologische Forschung. Zeitschrift für die Gesamte Neurologie und Psychiatrie, 172, 500-530.

Taylor, A., and Davey, M. R. (1968). Behaviour of jaw muscle stretch receptors during active and passive movements in cats. Nature, 220, 301-302.

Westbury, D. R. (1972). A study of stretch and vibration reflexes of the cat by intracellular recording from motoneurones. Journal of Physiology, 226, 37-56.

Yu, S.-K. J., Schmidt, A., and Sessle, B. J. (1973). Inhibitory effects of jaw muscle activity of innocuous and noxious stimulation of facial and intraoral sites in man. Archives of Oral Biology, 18, 861-870. 